\title{
Colonizing Safety: Creating Risk through the Enforcement of Biomedical Constructions of Safety
}

\author{
Paul Kadetz \\ Received: $\square$ / Accepted: \\ (C) National Science Council, Taiwan 2013
}

\begin{abstract}
In the normative health care discourse, safety is represented as a concept that is at once universal, irrefutable, and inherently beneficent. Yet, research at local levels in the Philippines challenges these assumptions embedded in the biomedical construction of safety. This article examines how the imposition of a biomedical construction of safety onto a given local group, which does not share this construction of safety, can affect the local group. Specifically, this article examines the application of the biomedical construction of safety to the regulation and control of local nonbiomedical practices and practitioners in the rural Philippines. This twenty-twomonth field research was carried out through interviews, focus groups, and participant observation within communities of four rural municipalities in the Philippines and with stakeholders at state and multilateral levels. The case study of the implementation of safe delivery through the insistence on in-facility birthing with "skilled birth attendants" and the cessation of training for traditional birth attendants provides an illustrative example of the need for more nuanced and complex understandings of safety and risk within any given context. This research identifies that the enforcement of an etic conception of safety onto any given group can, ultimately, compromise the safety of that group.
\end{abstract}

\section{Introduction}

In the normative biomedical health care paradigm, safety is represented as a concept that is at once universal, irrefutable, and inherently beneficent. Yet, research at local levels in the Philippines challenges such assumptions embedded in the biomedical construction of safety. This article briefly contextualizes the normative (biomedical) construction of health care safety and examines the application of this construction to the regulation and control of local nonbiomedical practices and practitioners in the rural Philippines. This research identifies that the enforcement of a concept of safety that is foreign to a given group can, ultimately, compromise the safety of that group.

P. Kadetz $(\bowtie)$

Leiden University College, The Hague, Anna van Buerenplein 301, 2595 DG The Hague, the Netherlands e-mail: paulkadetz@gmail.com 
This research was conducted in communities of four rural municipalities ${ }^{1}$ of the Philippines over a period of twenty-two months. The sample of 1,023 informants consisted of community members, community leaders, health care providers, and policy actors who participated in semistructured interviews, focus groups, and pile sorts. Participant experience was also compiled over a year-long period in both the Traditional Medicine Unit of the Western Pacific Region Office of the World Health Organization (WHO) and the Philippine Institute of Traditional and Alternative Healthcare of the Department of Health of the Philippines (DOHP).

\section{Framing the Normative Discourse of Safety}

Common themes of the normative discourse of safety, particularly identified in the risk management literature, are, first, that dangerous threats of the unknown can be known; second, that science and technology provide the means by which to identify and control danger; and third, following the precautionary principle, that risk is to be assumed until safety is proven (Andorno 2004). Danger resides in the unfamiliar and unknown, in leaving one's own "community" where the rules are understood and more or less fixed in a particular cosmology and order (Douglas 1966). Danger is propagated through social education. "Cultural notions tell us intuitively what is potentially dangerous and harmful and what is not" (Boholm 2003: 161). Although much of the risk literature locates the unknown in the future, danger can clearly lurk in the present.

In general, danger is located in that which threatens the integrity of what is known and understood (or that which is socially constructed as a threat, as exemplified in the current discourse of "terrorism"). Therefore, I would argue that though danger may concern temporal anxiety about the future, danger is more often located in the Other.

Mary Douglas (1966) identifies that what is particularly dangerous about the Other is the threat their systematic order poses to the integrity of the Self's order or what Pierre Bourdieu (1977) would identify as the doxa of the Self. Every system of order contains within it the understanding and meaning needed to facilitate the means for navigation through life, essential for any given group. These systems of order, which I refer to here as ordered systems of understanding and meaning, are foundational to social structure. Thus, the integrity of these ordered systems of understanding and meaning is precisely what is being threatened when one system, such as biomedicine, dictates a hegemonic construction, such as safety, for all Others to follow. Thereby, what the Western Self determines to be safe is to be considered safe not just for the Western Self but for everyone.

Interestingly, the idea of the preservation of wholeness is embedded in the Latin derivation of the word safety, solidus, meaning solid and stemming from the ProtoIndo-European base of solwos, which means whole (Nilsen et al. 2004). Hence, the idea of maintaining the integrity of the whole is etymologically embedded in the

1 The municipalities of Bagabag, Bontoc, and Sadanga are located on the island of Luzon, and Murcia is located in Negros Occidental. 
meaning of safety. Thus, it can then be understood how an imposition of safety can potentially compromise the integrity or wholeness of the Other's order.

If societies function, at least in part, as mechanisms of safety, then ritual can be understood as the social means by which to control the dangers of the unknown. That which in many cultures is conceived as danger, modernity operationalizes as "manageable risk." Risk analysis, then, is a modern ritual for coping with uncertainty and danger, in which the belief in the power of science and statistics to protect replaces the belief in protection by deities. In effect, religious determinism has been replaced by the statistical determinism of the probabilities of risk. It is questionable whether the evidence-based movement of the late twentieth century that has been so zealously adopted, particularly in the field of biomedicine, has not been a conservative reaction to the quandary of postmodern indeterminism via a deterministic renewal in the belief of science's omniscience and control.

The calculation of risk (or risk assessment) can thereby be understood as a ritual of rationality. Yet, as Åsa Boholm identifies: "The concept of risk . . . integrates descriptive/factual and normative components and is therefore (intrinsically) open to negotiation and contestation" (2003: 160). Thus, safety is composed of the prescribed activities, or the idiosyncratic ways to execute these activities, that are (socially) rendered appropriate in order to lower risk, minimize uncertainty, and regain a sense of control over the unknown. Safety, then, is a socially prescribed form of agency employed to protect oneself and/or one's group. Ultimately, safety can be understood as a foundation upon which social structure is constructed and through which hierarchies of power can be rationalized and maintained.

\section{Safety: A Central Pillar of Traditional, Complementary, and Alternative Medicine Policy}

The biomedical construction of safety has been successful both in substantiating biomedicine's role in colonial and postcolonial discourses and in facilitating the reception of Western modernity and Western liberalism into social systems worldwide (Arnold 1988). Policy that is constructed from a biomedical perspective establishes an expectation in both practitioners and lay public for a similar conformity to biomedical standards by nonbiomedical practitioners and practices. A pervasive and often sanctimonious assumption of the centrality of safety is shared in much of the traditional, complementary, and alternative medicine (TM/CAM) policy literature. However, markedly lacking in this discourse is the consideration that safety is a social construction and thereby particular to a given cultural, social, and individual context or, rather, particular to a given ordered system.

The TM/CAM policies of the WHO reflect a biomedical paradigm of order that primarily serves to protect its own integrity. The employment of this paradigm can be identified in WHO documents ranging from the guarded initial recommendations of the "appropriate use" of nonbiomedical practices by the World Health Assembly in 1977 to policies calling for the standardization and regulation of nonbiomedicine in terms of safety, efficacy, quality, access, and rational use (WHO 1977, 2002a; Bodeker and Burford 2007). The biomedical concerns for the safety of nonbiomedical practices and practitioners have resulted in an intensified focus on the standardized 
training and regulation of nonbiomedical practices and practitioners in WHO TM/ CAM policies.

\subsection{Deconstructing "Safety" in the Normative WHO TM/CAM Policy Discourse}

Prior to the Declaration of Alma-Ata in 1978, little literature or international discourse concerned formal TM/CAM policies beyond the national level of certain countries. However, after 1978, and especially into the 1980s, there was an exponential leap in publications concerning TM/CAM policy, particularly from the WHO. In analyzing this literature, several words appear repeatedly in almost every WHO document related to TM/CAM policy and guidelines. For example, WHO defines "its role in TM/CAM by developing a strategy to address issues of policy, safety, efficacy, quality, access and rational use of traditional, complementary and alternative medicine" (WHO 2002c: 1). In the 2002 WHO Strategy for Traditional Medicine, the term "safety" appears seventy-four times. The 2002 WHO Western Pacific Region Office (WPRO) Strategy states: "Safety is the primary concern in medical treatments- to patients and practitioners alike. Formal standards of safety for medication and nonmedication treatment modalities are to be established by Ministries or Departments of Health or other governmental agencies" (WHO 2002a: 20).

Three primary assumptions in this statement will be examined throughout this article. First is the assumption that safety is a primary concern of patients regarding local health care practices. In research conducted in the Philippines, a markedly low percentage of informants (18 percent or less) had any concerns regarding the safety of their local health care practices. The second assumption, which stems from the first, is the ethnocentric perception that the biomedical construction of safety is universally shared. Again, this was not found in the research conducted at local levels in the Philippines. Lastly, by doing what is thought to be best for the other's own good, a justification of paternalism is clearly illustrated in this statement. Furthermore, this perspective assumes that a treatment identified as appropriate, that will work, and is safe cannot be determined by a patient but, rather, can be decided for the patient only by an outside "expert." Such a perspective poses marked issues when the patient's conception of safety does not conform with that of the expert.

\subsection{Contextualizing the Construction of Safety in the Traditional Medicine Unit at WHO}

The hegemonic control of biomedicine in singularly determining the standards of safety for all health care practices can, at least in part, be traced to the 1910 "Flexner Report," which attempted to standardize and control biomedical education in North America. In order to generate a full publishable situational analysis of American medical education, the American Medical Association invited the Carnegie Foundation to conduct a report on the state of North American medical schools (Starr 1982). Implementing the recommendations of the Flexner Report led to the subsequent closure of over half (eighty-four) of North American medical schools from 1919 to 1928, as well as the majority of nonbiomedical schools (Chapman 1974: 106). Of the seventy-six schools remaining, all offered the same curriculum, set the same 
academic standards, and followed the same entry requirements (ibid.). Thereby, they constituted a coherent ordered reflection of the biomedical Self.

In his 1910 report, Flexner asks if "sectarian medicine," which he defines as allopathy, homoeopathy, and osteopathy, is "logically defensible" and "justifiable ... in this era of scientific medicine." He extrapolates that "modern medicine uses knowledge with no preconceptions," whereas "men possessed of vague preconceived ideas are strongly disposed to force facts to fit, defend, or explain them," thereby interfering with "the free search for truth." He concludes that "modern medicine denies outright the relevancy or value of allopathy or homoeopathy" (156). Thereafter, "truth" in health care became the sole self-proclaimed domain of biomedicine and the biomedical expert. Thus, only by submitting one's ordered systems to the dominant biomedical system could the nonbiomedical Self hope to survive.

What is so powerful in Flexner's statement is the representation of the modernization and scientization of health care as a moral imperative. A century later this moral imperative can be found in WHO's discourse of safety. The WHO's specific emphasis on the safety of TM/CAM may, at least in part, be understood as an outcome of the organization's restructuring and streamlining after the departure of Halfden Mahler, the director-general of WHO from 1973 to 1988 (Lee 2009), who was instrumental in the introduction of TM/CAM policy at the WHO and under whose direction traditional medicine (TRM) units were formed at WHO headquarters and regionally. According to informants, Mahler's successor, Director-General Hiroshi Nakajima, restructured the TRM Unit under the management of the Department of Essential Medicines of WHO. In a chronological analysis of WHO publications, there is a clear division in the priorities and content of the guidelines published by the TRMUnit before and after this reorganization. Specifically, the WHO's traditional medicine discourse shifted from issues of access and primary health care to distinctly more pharmacological and commodified priorities of good agricultural and collection practices (WHO 2003), herbal regulations (WHO 2005), good manufacturing practices (WHO 2007b), and quality for herbal medicines regarding contaminants and residues (WHO 2007a).

The term safety appeared with far greater frequency in WHO TM/CAM publications after the restructuring of the TRM Unit under the Department of Essential Medicines. Thus, with a renewed emphasis on herbal medicines, commodification, and manufacturing, the original ordered system of understanding and meaning of the TRM Unit was replaced by the ordered system of the Department of Essential Medicines. This new prioritization was simultaneously reflected in the concerns of WHO member states of the Western Pacific Region on international trade and safety issues, such as labeling of raw herbs, reduction of heavy metal content, and the domestic and nondomestic production of herbal products.

In reviewing both WHO/WPRO and Association of Southeast Asian Nations documents pertaining to health care integration and "traditional medicine" of the past ten years, I assessed the frequency with which certain concerns were reported by member states. Ten out of thirty-seven WHO member states in the Western Pacific Region reported concern with the safety and good manufacturing practices of imported herbs and herbal products. Documents revealed that Japan was particularly concerned with the raw herbal products they were receiving from China, which were found to contain large amounts of heavy metals. And yet this information did not appear to be openly discussed at the WPRO, apparently for diplomatic reasons. My research corroborates 
Javed Siddiqi's (1995) conclusion that the WHO is predominantly a political organization concerned throughout its history with political controversies as varied as apartheid, Zionism, and nuclear disarmament. Hence, the priorities of the TRM Unit of the WHO can be understood to be, at least in part, an outcome of political and economic diplomacy that has been disseminated through a biomedical discourse concerning the safety of TM/CAM practices.

\section{The Construction of TM/CAM Safety at the State Level in the Philippines}

Biomedical hegemony has influenced the construction of safety concerning TM/CAM not only at the global/multilateral level but also at the state level. The powerful Philippine Medical Association (PMA) has been one of the primary opponents of the population's continued use of nonbiomedical practices and practitioners and, according to informants, has successfully thwarted the full adoption of laws advocating the use of TM/CAM in the Philippines. According to informants, the reason for this opposition was justified as a paternalistic concern with safety.

In interviews with PMA leadership, I was told that "we do not subscribe to "quack medicine' where there is no scientific basis. It is the scientific fact that is important, and using the WHO standards plus the tenets of our code of ethics [sic] is no harm. Safety is the primary concern of our code of ethics ... so the PMA is supporting traditional medicine as long as it is in line with the WHO and the PMA code of ethics." The PMA informant's statement is important for several reasons. First, it offers a clear illustration of the force of biomedical hegemony in controlling nonbiomedical practices at a state level. Either the local group's ordered system adheres to the rules of biomedical order, or it will be rejected as "quack medicine," Second, the influence of the WHO and their policy, especially concerning safety, is illustrated here. And lastly, this statement clearly reflects the same justification of biomedical expertise (i.e., as an ethical and moral imperative) as was identified in the Flexner Report.

\section{The Perceptions of Safety Concerning Local Level Health Care Practices}

The normative biomedical representation of safety of TM/CAM at global and state levels is problematized at the local level. Though safety of nonbiomedicine is a primary concern identified in almost every WHO health care integration document, many barangay $^{2}$ (community) informants in rural areas of the Philippines could not understand why they should be concerned with the safety of the practices of their albularyo (herbalist) or their supok (faith healer). Less than one-quarter of the 728 barangay informants in any of the communities of the four municipalities assessed reported any concern about the safety of local health care practices and practitioners. And less than 3 percent of all informants in any barangay reported ever having any concerns of safety specifically regarding hilots (traditional birth attendants) (table 1).

2 The barangay, or village, signifies the basic administrative unit in the Philippines, a subdivision of a municipality predating Spanish colonialism, historically related to tribal units in Philippine antiquity. 
Table 1 Barangay informant perception of safety of their nonbiomedical practitioners

$\%$ Barangay informants

\begin{tabular}{lcrrr}
\cline { 4 - 5 } Concerns of safety regarding & Bagabag & Murcia & Sadanga & Bontoc \\
\hline Local health care practices/practitioners & $13 \%$ & $18 \%$ & $5 \%$ & $9 \%$ \\
Hilots & $3 \%$ & $2 \%$ & $1 \%$ & 0
\end{tabular}

When barangay informants did identify concerns with the safety of local health care practices and practitioners, these were most often identified in relation to biomedicine. For example, some barangay informants were concerned that local nonbiomedical practitioners did not have the proper diagnostic equipment to make a biomedical diagnosis and that they are therefore incapable of handling a "serious illness." However, in general, the predominant sentiment was that unless a local practitioner gives one reason for concern, there is no conception of risk with local practices. Furthermore, the idea of considering their nonbiomedical practitioners as a risk was completely foreign to barangay informants. In fact, the idea was so foreign that most of the barangay informants queried did not understand the question of being concerned with the safety of local practices and practitioners. One forty-five-year-old female from Bontoc Ili, Bontoc, explained: "Our barangay is like our family. You are not generally afraid of your family. When your mother picks herbs for you, are you going to worry that they are not safe? We grew up with our albularyo - whyswe would we be afraid of her?"

Pat Caplan notes that "global risks ... could only effectively be countered by knowledge which is localised and dependent upon social relationships of trust" (2000: 8). Yet, the inherent trust, identified in the statement above, is not considered in the risk discourse. The importance of social relationships to the perception of safety is clearly illustrated in the informant's reponse.

Even in biomedical contexts, trust is informed by social relations. A study by Webster et al. (2009) noted that, "for most of our respondents, safety was framed in terms of knowing someone ... with a history of similar difficulties ... and this provided them with a personal reference point, a sense of reassurance that the drug was tried and tested and 'well-proven' among people they knew well.... Safety is then dependent on mobilising social relations and a mix of lay and professional knowledge and practice" (239-40). Hence, such local, as well as individual, meanings inherently problematize a paradigm of global health policy, which is structurally designed to accommodate a singular universal biomedical interpretation of safety. Furthermore, it may not be completely accurate to conceptualize safety as solely defined by the given group's local field. For example, one forty-six-year-old male informant understood safety in a quite personal manner. Safety is an issue he identifies only with certain local practitioners: "How could they support their diagnosis without having laboratory results. They might predict or diagnose their patients by 'preassumptions' $[\mathrm{sic}]$ only ... this is very dangerous." Yet, later in the interview he identified hilots as "the first choice of pregnant mothers because they are very skilled and confident to deliver." Thereby, this informant created his own idiosyncratic distinction between 
those local practitioners that should be judged according to a biomedical standard and those that are exempt from such judgments due to their proven skill. Thus, safety may be understood to be both socially and individually constructed. Therefore, safety may be better understood as a concept that encompasses local social meanings, familial meanings, and individual meanings, in addition to the selective adoption of normative global meanings adopted by the state and their agents. Safety is then both socially and individually determined in combinations that can be unique and specific to a given context.

\section{6 "Just Do What I Say": Problematizing Safety as a Function of Standardization}

Standardization is commonly conceived in the normative risk discourse as a means to achieve safety. For example, in commercial airlines not only are all pilots and flight crew trained in a globally standardized way, but planes are standardized, airports are standardized, and even what is spoken by the flight crew is standardized. Thereby, through rigid standardization, all commercial air travel is meant to be equally safe regardless of the particular airport, airplane, or airline. Thus, standardization is represented as a means to achieve safety. This belief appears to stem not only from the need for reproducibility in modern Western science, but also to some extent from Western industrialization and Fordism, in which the conception of safety is epitomized by the standardized replication of the products of an assembly line.

Standardization of local health care practices and practitioners along a biomedical model is commonly identified as a means to attain greater safety in local practices and is often a first step for any considerations of integrating local practices into a biomedical health care system. In both the literature reviewed and interviews with the DOHP and the WHO, it is either assumed or not considered whether local nonbiomedical practitioners will (a) be capable of being standardized, (b) agree to participate in standardized training, and/or (c) alter their practices according to their standardized training.

The findings from local Filipino practitioner interviews problematize many of these assumptions. Although the majority of local practitioner informants reported that they would want to attend standardized training, many identified practical obstacles that would prohibit them from actual participation. These obstacles include transportation to the training sessions and understanding what is being taught. Furthermore, many of the local practitioners interviewed had no formal education and were illiterate, and indicated that they would be disinclined to attend training if literacy was expected.

However, several informants reported that even if they were willing and able to attend standardized training, they would not agree to simply alter or abandon their practices in order to comply with standardized training. Their reasoning identifies a fundamental misunderstanding in the TM/CAM safety discourse that is directly related to the ordered systems of understanding and meaning of these local practitioner informants.

All local practitioner informants interviewed understand their work in terms of a relationship to "God." They do not separate their practice from their "religious convictions," as dictated by their shared doxa of the barangay Self. Regardless of 
their practitioner designation or their geographic location, almost every local practitioner interviewed relayed a similar story of how they became a practitioner. A thirtyeight-year-old female supok's story is illustrative:

I was in my early twenties and I became very ill. I had a high fever for days. I don't remember if I was dreaming, but an old woman came to me. I think it was the Virgin Mary. And she said, "You must do what God asks you to do or you will die." I became more ill until, I was told, I died. I was told they put me in a casket and everyone came to mourn. And then, the next day before they were going to bury me ... I "woke" up. Almost right away everyone knew, and there was a line outside my door of people waiting to be healed. I didn't know what to do, but I remembered what the old woman told me. Suddenly, I started hearing this man whisper in my ear what I should do for each patient. I would do what he told me, and they would always get better. And I know if I stop doing what God wants me to do, I will die again.

Although this particular informant's story was unique, the elements of her story were repeated by almost every practitioner interviewed: (a) An illness that is severe or life threatening creates a liminal state in the informant. (b) They then experience a visitation from an elderly man, woman, Catholic saint, or other religious representation, in either a dream or a vision. (c) In this visitation informants are told to comply with God's request for them to perform healing for their barangay or they will suffer and die. (d) The original entity in the vision/dream or a new entity teaches them how to practice, again through dreams or visions.

Thus, we can identify two fundamental issues with attempting to standardize these local practitioners for the purposes of safety. First, the local practitioners interviewed are all practicing their given health care practice(s) differently and according to their own standards, which would problematize any attempt at standardization that would normatively assume bounded health care practices or practices that could be systematized. Second, and more problematic, is the assumption that standardized practices can and will be adopted, regardless of whether these practices alter or replace a local practice that has quite specific meaning and understanding to each practitioner, as well as to their patients.

From field observations, it was clear that local practitioners will do what is necessary to maintain the integrity of their practices and thereby the integrity of the community's ordered systems of understanding and meaning. Thus, in this manner local practitioners believe they are practicing safely. Local practitioners stated that they would not simply do what they were told to do from the agents of the DOHP. They considered it impossible to comply with the DOHP, when they are beholden to answer to "God"; who is requesting that they practice as they were "taught." Thereby, to not practice in the manner informants believe that they are meant to practice, or to refuse a patient in need, is perceived as akin to refusing "God's will" and thereby jeopardizing the safety of the practitioner, their family, their patients, and their barangay.

Furthermore, local practitioner informants found the concept of standardization of their practices inherently ignorant, for they believed that what was given to them as a gift from "God" could neither be taught nor standardized, nor should it be shared. 
Table 2 Standardization of local (nonbiomedical) practitioners

\begin{tabular}{|c|c|c|c|c|c|}
\hline \multirow[b]{2}{*}{ Indicator of health care integration } & \multirow[b]{2}{*}{ Informant } & \multicolumn{4}{|c|}{$\%$ Local practitioners } \\
\hline & & Bagabag & Murcia & Sadanga & Bontoc \\
\hline \multirow{4}{*}{$\begin{array}{l}\text { Had received any formal or } \\
\text { informal training for their practice }\end{array}$} & Hilot & $100 \%$ & $86 \%$ & - & $100 \%$ \\
\hline & Albularyo & $50 \%$ & $0 \%$ & $0 \%$ & $0 \%$ \\
\hline & Supok/faith healer & $0 \%$ & $0 \%$ & $0 \%$ & $0 \%$ \\
\hline & Bonesetter & - & $100 \%$ & $100 \%$ & $100 \%$ \\
\hline \multirow{4}{*}{$\begin{array}{l}\text { Would be willing to participate } \\
\text { in standardized training }\end{array}$} & Hilot & $100 \%$ & $100 \%$ & - & $80 \%$ \\
\hline & Albularyo & $50 \%$ & $100 \%$ & $100 \%$ & $100 \%$ \\
\hline & Supok/faith healer & $67 \%$ & $60 \%$ & $100 \%$ & $100 \%$ \\
\hline & Bonesetter & - & $100 \%$ & $100 \%$ & $100 \%$ \\
\hline \multirow{4}{*}{$\begin{array}{l}\text { Would change their practice } \\
\text { according to their standardized } \\
\text { training }\end{array}$} & Hilot & $100 \%$ & $100 \%$ & - & $100 \%$ \\
\hline & Albularyo & $0 \%$ & $0 \%$ & $0 \%$ & $33 \%$ \\
\hline & Supok/faith healer & $0 \%$ & $0 \%$ & $0 \%$ & $0 \%$ \\
\hline & Bonesetter & - & $0 \%$ & $50 \%$ & $0.00 \%$ \\
\hline
\end{tabular}

However, in the normative conceptualization of standardization and safety, such sociocultural variation is not considered (table 2).

It is also noteworthy that, although all hilots, along with one bonesetter and albularyo, reported that they would change their practices according to their standardized training, no local practitioner informant interviewed would agree to completely abandon their own practices for the purpose of biomedical standardization. Rather, they would agree to selectively choose what to incorporate into their own practice. Hence, such integration would not conform to the criteria of biomedical safety, but rather, those chosen bits of biomedical information that local practitioners can interpret as appropriate would be adopted and integrated into their practices according to their own criteria.

Furthermore, the issues of standardization identified by local practitioners were also identified by barangay members. Several barangay informants reported that they treat themselves and their families primarily with herbs picked from their own garden, for which they claim they were directed to pick by "God." A sixty-two-year-old female from Samoki, Bontoc, who had delivered eight babies at home, stated: "God will help me at home. That is where I am intended to deliver."

Barangay informants indicated that local practitioners serve important social and cultural functions in their communities. Thereby, informants expressed concern that their local practices could be altered to the point of being no longer socially meaningful, or specifically able to address what would be categorized as "culture-bound illnesses." However, insistence on a particular standard of safety that is external to a given group's standard of safety and that ignores a given group's needs does not merely problematize local practices but can, in some contexts, compromise the safety of that group, as illustrated in the case of the eradication of hilots. 


\section{The Case of Traditional Birth Attendants: Creating Unsafe Health Care through an External Imposition of Safety}

\subsection{Fuzzy Data and Dismissal}

According to the WHO, initial assessments of traditional birth attendant (TBA) training programs, that began as early as the 1950s, demonstrated a reduction in maternal and infant mortality that purportedly "reached a plateau" in the 1990s (Kruske and Barclay 2004: 307). The identification of this "plateau" in the data triggered a dramatic shift in TBA policy, which included the cessation of training and discouraged or prohibited the use of TBAs worldwide. This new policy toward TBA training and integration was formally announced in a 1992 joint WHO/UNFPA (United Nations Population Fund) statement declaring that the training and use of TBAs should be used only as an interim measure until all women have access to "acceptable, professional, modern health services" (WHO 1992). "Four years later, WHO policy leaders insisted on 'skilled' rather than 'trained' birth attendants" (Kruske and Barclay 2004: 307). This was a significant policy change, as it is believed that (globally) "two-thirds of all births occur outside health facilities" (Bergström and Goodburn 2001: 79).

However, the literature suggests that these reported stagnant reductions in infant and maternal mortality rates may not reflect a TBA's innate ability to learn specific birthing techniques, as much as what and how TBAs were taught and particularly how this training was evaluated. According to Staffan Bergström and Elizabeth Goodburn: "One of the reasons for continuing debate over TBA training is the haphazard way the programmes have been evaluated ... there are surprisingly few methodologically sound evaluations, even of programme outputs" (2001: 84). The variety of training outcomes between countries corroborates this observation. For example, TBAs were considered to have been successfully integrated into health care systems that demonstrated consistent marked reduction of maternal and infant mortality in both Malaysia and Samoa (Kruske and Barclay 2004). Furthermore, the multiple complex factors that can contribute to maternal and neonatal mortality (including malnutrition, infectious environment, and poor prenatal/postnatal care) appear to be statistically ignored in many of these analyses in which maternal and infant mortality is being used as the only indicator by which to measure TBA competence and safety.

But even if we ignore the myriad issues identified in using maternal and infant mortality data as a proxy for the safety of TBA delivery and the success or failure of TBA training, the findings of the WHO studies are fundamentally problematic because of their questionable rigor. Issues have been identified with unreliable data sets and inappropriate data analysis employed in these reported findings of stagnant maternal and infant mortality rates. An independent analysis of neonatal and maternal mortality from the Institute for Health Metrics and Evaluation (IHME) at the University of Washington used "three times as much data as the previous researchers" and demonstrated that globally neonatal mortality rates fell by 57 percent from 1970 to 2010, with the greatest reduction in neonatal mortality in the period from 1970 to 1980, a period of intense WHO/UNICEF TBA training globally (Rajaratnam et al. 2010). However, the researchers also noted a slight leveling in this reduction from 1990 to 2010, which was actually during the period when WHO/UNICEF TBA training had begun to cease (ibid.). 
Similarly, in terms of maternal mortality, IHME identified a 35 percent decrease in maternal mortality from 1980 to 2008 globally (Hogan et al. 2010: 1609). If maternal deaths are statistically controlled for global HIV seroprevalence, the maternal mortality shows a 47 percent decrease during this period (1613). Therefore, a significant proportion of maternal mortality may, in actuality, be more a result of access to antiretrovirals than of delivery by TBAs. These findings are in sharp contrast to the jointly sponsored WHO, UNICEF, UNFPA, and World Bank assessment reporting " 576,300 maternal deaths globally in 1990, and 535,900 maternal deaths in 2005," or a mere 7 percent decrease in maternal mortality over fifteen years (1609).

Although causality cannot be determined from this data, and though the IHME research does not specifically analyze TBA training as a factor in their research, both their findings and those of the WHO identify the most marked global declines in maternal mortality rate as occurring during the final years when TBA training was still provided by WHO/UNICEF (1990-95), while the largest increases in maternal mortality rates occurred after global WHO/UNICEF TBA training had ceased (19952000) (Hogan et al. 2010: 1612).

Furthermore, as mentioned, it is imperative to note that even though the WHO has been emphasizing the importance of analyzing health care from a health systems perspective for well over a decade, a health systems approach has been patently deemphasized in the WHO/UNICEF literature on maternal and infant mortality, by analyzing TBAs, in a markedly reductive manner, as the sole factor (of all the possible complex factors in a given health care system) affecting maternal and infant mortality. However, in recent research in which maternal and infant mortality has been assessed as a complex package in which TBAs are an integral, but not the sole or even most significant, component, TBA training has been identified as effective and successful in promoting safe delivery (Sibley et al. 2009; Carlo et al. 2010; Midhet and Becker 2010; Bhutta et al. 2011; Gill et al. 2011). Similarly, Bergström and Goodburn note that "there is no conclusive evidence that trained TBAs can prevent maternal deaths unless they are closely linked with existing health services, and are supported to refer women to functioning hospitals providing essential obstetric care" (2001: 79).

Hence, what is relevant here is that the quantitative methods that are being employed to measure (and ultimately discredit) the safety of TBAs and the failure of TBA training to develop safe TBAs rely on data and data analysis that may be compromised, inaccurate, incomplete, or highly aggregated. Thus, the data collection and analysis substantiating an exclusionary and strictly biomedical paradigm of safety in maternal and child health care may, in actuality, be more a reflection of global and multilateral politics, economics, and biases than of any statistical neutrality.

\subsection{The Adoption of Problematic Logic: "If We Don't Train Them, They Will Just Go Away"}

Since 1952, UNICEF and the DOHP have conducted training for hilots throughout the Philippines "as part of the country's midwifery programme" (Vuori 1982: 131). In fact, these particular hilot training sessions in the Philippines have been identified as the impetus for the WHO's original interest in local nonbiomedical health care. The training focused on sterile and hygienic techniques, prenatal and postnatal education, and the warning signs of complications requiring referrals to hospital (WHO 1975). 
Hilots were especially discouraged from the practice of cutting the umbilical cord with bamboo and were provided with sterile birthing kits. Hilots interviewed found the training useful, reported that they had practiced what they were taught, and were eager for more training. Some informants revealed they have kept their birthing kits since their initial training in the 1950s.

In 1958, Republic Act 2644 authorized hilots to practice in areas not served by professional health workers (Republic of the Philippines 1958). In 1981, with the adoption of primary health care, trained hilots were recognized as qualified members of the Women's Health Team (ADB 2007). In the field, I noted that trained hilots were considered part of the health care team even at the municipal level of the rural health unit. For example, in the Murcia rural health unit, a roster kept on a wall of all the health care workers in the barangays included the category of trained hilots. Vuori (1982: 131) notes that "hilots were encouraged to involve themselves in a wide variety of community health activities, such as notifying communicable diseases, organizing mothers' classes, registering births, helping to arrange mother and child referrals to health centres and hospitals, assisting in immunization and collaborating in family planning." Hilots were quietly integrated into most local health care systems in the Philippines. Furthermore, a 2004 USAID report stated that hilots were used by women even when physicians and midwives were readily available in their area. According to the study, hilots attended to 63 percent of deliveries for "poor women" and 23 percent for the "non-poor" (USAID 2004). However, regional differences can be identified in the use of hilots. In certain regions of the Philippines, half or more deliveries are attended by hilots regardless of socioeconomic status (ADB 2007). In general, it appears that the farther from the capital of Manila, the higher the reported use of hilots.

From 2004 to 2008, the World Bank, USAID, European Commission, and Asian Development Bank (ADB) issued reports concerning the funding of a project to reduce infant and maternal mortality in the Philippines via "skilled" deliveries within in-birthing facilities (USAID 2004; ADB 2007; European Commission 2008). The ADB's independent evaluation was the only report to recommend not funding the project. ADB (2007) identified the project as both infeasible and unsustainable, noting the seriously flawed data sets and statistical analyses provided by the DOHP. Unlike the other evaluations, ADB's suggested that the development of in-birthing facilities was a project that, even if implementable, could be implemented only in small stages over time and that hilots continuing to attend to at-home births was essential for this process to occur.

The director of this ADB evaluation stated, in an interview, that the concern was that the cessation of training of hilots and the lack of a provision of sterile birthing kits would not dissuade women from seeking the help of hilots. Nor would this policy encourage hilot compliance, for the priority that hilots give to community women is dictated by their cultural role. Similarly, although several hilot informants reported being relieved to be able to give up their roles, all stated that they would not be able to refuse a woman requesting their help.

Furthermore, the ADB evaluator identified numerous issues in the correlation of infant and maternal mortality rate with hilot deliveries. Similar to the issues of rigor identified in the global WHO/UNICEF data, in assessing the DOHP data the independent evaluators at ADB noted that essentially all at-home deliveries that resulted in maternal and infant mortality were statistically attributed to hilots, regardless of who 
assisted delivery - very often it was a family member or the mother by herself-or whether it was a purposeful abortion (ADB 2007). Furthermore, Victoria Bautista notes that "all of the [DOHP] program implementation review reports begin with the caveat that data on infant and maternal mortality are unreliable" (1994: 69). The unreliability of the DOHP data appears to be further corroborated by the aforementioned IHME analyses. In their country-level analyses, IHME identified significantly higher reductions in maternal and under-five mortality in the Philippines than what is identified in the DOHP findings, with the most significant reductions from 1980 to 2000 , the period with the reportedly highest number of hilot training sessions.

The ADB evaluator noted that when her team disaggregated the DOHP data, purportedly serving as the main data set for all of the above-mentioned reports, they found that the training of hilots substantially reduced maternal and infant mortality in the Philippines and that the far lower number of in-facility deliveries actually resulted in a higher relative proportion of infant and maternal mortality. Although these conclusions appear counterintuitive, Vicki Penwell (2009) commonly identified poor hygiene, lack of medical equipment, lack of sterile technique, and lack of appropriate care in labor and delivery and in neonatal intensive care units of selected Philippine hospitals. However, it is also possible that facility-based and biomedical deliveries may be associated with higher maternal and infant mortality rates, because those mothers who went to hospital may have already been at greater risk in delivery than those who remained at home or with a hilot.

Regardless of the rigor of the data, the DOHP, with the help of substantial loans from the remaining project lenders, issued an administrative order in September 2008 to institute mandatory in-facility birthing (DOHP 2008). This order states that all women in the Philippines are to be considered at-risk during pregnancy and must deliver only in-facility by skilled professionals (i.e., physicians and biomedical midwives). Hilots are to be integrated into the maternal child health team only if they agree to not perform deliveries again. Hence, there is to be no further training of hilots, and they will no longer be provided with sterile birthing kits. It is simply assumed that all hilots and all women will comply with this administrative order.

When I queried the director of the Maternal Child Health Unit of the DOHP, who developed the policy, about the feasibility of the project, especially in rural areas, she replied: "We are already building birthing facilities all over the Philippines. We have five years to get this going. Furthermore, we have incentives we can offer." She did not outline coherent plans beyond the fact that she perceived everyone would be eager to comply, including hilots. When I asked the reason for the urgency in executing the project, she replied: "The MDGs [Millennium Development Goals] ... we must meet the MDGs." It is noteworthy that in fully complying with the foundational global development policy of the MDGs, and the universal paradigms of safety embedded therein, that the safety of populations may ultimately be compromised, depending upon the appropriateness of MDG implementation for a given context.

\subsection{Assessing the Safety of the Eradication of Hilots via Barangay Members' Perceptions}

In assessing the safety of the DOHP administrative order for mandatory in-facility birthing employing only skilled attendants, it is important to examine the perceptions 
of barangay members concerning this policy. Approximately 300 female barangay members of the four rural municipalities studied were questioned in semistructured interviews regarding who delivered their children, whom they preferred to deliver their children, where they preferred to deliver their children, their reasoning for these preferences, the advantages and disadvantages to home and hilot delivery, any negative experiences they had or heard from others concerning hilots, if hilots should be allowed to continue to deliver, and if they perceived mandatory in-facility birthing with the prohibition of the practice of hilots appropriate for their barangay. These findings are summarized in table 3 .

Nearly half of the total deliveries of all informants ( 46 percent) were handled by a physician or midwife, and 36 percent of infants were delivered by a hilot. But it is important to note that few informants delivered all of their babies exclusively with hilots or skilled attendants; rather, a majority of informants delivered with both hilots and midwives or physicians, depending on their particular circumstances in each pregnancy. Furthermore, 66 percent of informants indicated a preference for delivery by a physician or midwife, and 19 percent preferred delivery by a hilot. However, 63 percent of informants indicated that they would prefer to deliver at home. However, home delivery is not necessarily the same as hilot delivery. Informants gave myriad reasons why it was not always possible to follow their preferences. For example, physicians do not perform deliveries outside of hospitals, and midwives will deliver only at home when they were available to do so. Therefore, even if women did not necessarily prefer hilots to deliver their babies, hilots provided one of the few options for assistance in home delivery beyond the available midwife, family member, or self-delivery. This may possibly explain why the rate of actual delivery by hilots (36 percent) is nearly double the preference for hilot delivery (19 percent).

Informants gave reasons such as cost ( 26 percent), comfort (24 percent), and lack of restrictions (16 percent) as the primary advantages of delivering at home, while 68 percent of informants identified emergencies during delivery as a potential disadvantage to delivering at home. Similarly, cost (58 percent), comfort (22 percent), and lack of restrictions (19 percent) were also identified as the primary advantages for hilot delivery. Inability to handle emergencies ( 37 percent) and lack of medical equipment

Table 3 Summary of barangay women's perception of hilots 
or medicines ( 25 percent) were identified as the primary disadvantages of delivery with hilots. Yet, only 2 percent of all informants reported having any complications with a hilot delivery. And, as indicated in table 1, less than 3 percent of informants reported any concern with the safety of hilots.

Furthermore, 77 percent of informants believed that hilots should be allowed to practice in their barangay regardless of the DOHP administrative order. Informants identified skill ( 23 percent), access ( 29 percent), and affordability ( 29 percent) as the primary benefits of hilots. Thus, the majority of informants believed hilots should be allowed to continue practicing even though only 36 percent of informants used hilots for delivery. Lastly, only 20 percent of all informants thought the DOHP policy for mandatory in-facility birthing was appropriate for their barangay.

\subsection{Further Factors Affecting the Safety of Hilot Eradication}

In general, the majority of informants perceived that hilots were safe and should not be prohibited from practice. Hilots were identified by informants to be highly skilled, always available, trusted members of the community and to always make women feel comfortable. Robert B. Stauffer notes: "Hilots reportedly were willing to give highly personal service, beginning to call at the end of the fourth month of pregnancy and visiting the prospective mother frequently from then on. They will come day or night and stay long hours if necessary" $(1966: 22)$. However, the primary reason that informants found the DOHP policy inappropriate was the shared perception that Filipino women would ultimately do what they wanted, regardless of DOHP policy. Further research with stakeholders identified myriad factors that could compromise this policy and ultimately pose a threat to the safety of pregnant women and infants.

\subsubsection{Financial access to in-facility birthing}

A predominant belief identified in interviews with policy makers at municipal, state, and multilateral levels was that all women, given the financial opportunity, would naturally want to take advantage of delivery in a hospital or birthing facility. In adopting this perspective, the only factor that could be understood to be preventing women from delivering in-facility is financial access.

According to informants, in order to replace at-home delivery by hilots, in-facility delivery costs for indigent women will be covered by the national health insurance, Philhealth, for up to US $\$ 130$ per delivery, for a maximum of four deliveries. However, barangay informants indicated that this amount does not fully cover the cost of inhospital delivery, and women still must pay for medications (before reimbursement by Philhealth), transportation to the facility, and any costs beyond the allocated coverage, all of which may be well beyond a family's budget. Furthermore, if there are complications resulting in costs beyond Philhealth coverage, families would be responsible for the difference. Yet, barangay informants did not generally identify financial access as the primary reason or even any reason they prefer to deliver at home. Throughout the Philippines home delivery was identified in from half to three-quarters of all deliveries, with a national average of 61 percent in 2003 (ADB 2007). Home deliver was preferred for several other reasons that barangay informants identified. 


\subsubsection{The perceived restrictions of in-facility birthing}

Only 37 percent of all barangay informants indicated a preference for in-hospital delivery, and less than 1 percent indicated a preference for a local birthing clinic or barangay health clinic. Regardless of the placement of the facility, several municipal health officers reported subsequent underutilization of in-birthing facilities. For example, informants from one rural barangay that opened the only birthing facility in the area in 2009 reported that, in that year, thirty-one women delivered at home and only one delivered in the in-birthing facility. When the women were queried why they did not use the new in-birthing facility, they stated that the table was too uncomfortable. The one woman who delivered in-facility agreed, stating that in the future she would not use the facility again. Informants stated that when they delivered at home they could deliver in whatever position they found comfortable. The least comfortable position for most women interviewed was reclining. And few indicated ever delivering on their back (Figs. 1 and 2).

Beyond the lack of comfort of the table or the position they must maintain, many women complained about the restrictive environment of hospitals. A sixty-eight-yearold female from Caliban, Murcia, delivered four children by herself and preferred this because "others hurry me... I like to take my time."

A twenty-nine-year-old female from Baretbat, Bagabag, stated: "If you go to hospital you will be forced to deliver immediately or you will be given a cesarean." In fact, several women stated that they preferred to stay home because they specifically did not want a cesarean delivery, reported as commonly performed in Philippine hospitals regardless of women's wishes. Furthermore, women stated that they did not want to "get cut," referring to the procedure known as an episiotomy, reportedly resulting in significant postpartum pain. ${ }^{3}$ Food restrictions, lack of privacy, not being allowed to bathe, being treated poorly, the presence of male obstetricians, and not having children near or restricting how many family members could visit were further issues that would dissuade women from delivering in hospitals or birthing clinics. One thirtyyear-old female in Anabel, Sadanga, stated, that the policy would be feasible only if the "government forces women into the facility." Culturally specific reasons for wanting to deliver at home also included a perceived risk inherent in leaving the home.

\subsubsection{The perceived risk of leaving the home}

One issue with constructing universal policies from the biomedical Self's ordered system of understanding and meaning is that Other's ordered systems, which are different from or in conflict with a biomedical understanding, will often not even be considered. For example, in an indigenous tribe in Mindanao, women believed that wherever they were in their household when they realized they were pregnant is where they are beholden to deliver in order to ensure a safe delivery. From this particular group's ordered system, risk was associated with not only delivering outside of the home but also delivering away from the exact spot in the home where the woman first realized she was pregnant. Thus, for these families, safety was perceived to be preserved by remaining at home. Facilities would be considered an extremely high risk

\footnotetext{
3 In an episiotomy, a surgical incision is made on the posterior vaginal wall prophylactically in order to reduce vaginal tears as a result of childbirth (Thacker and Banta 1983).
} 


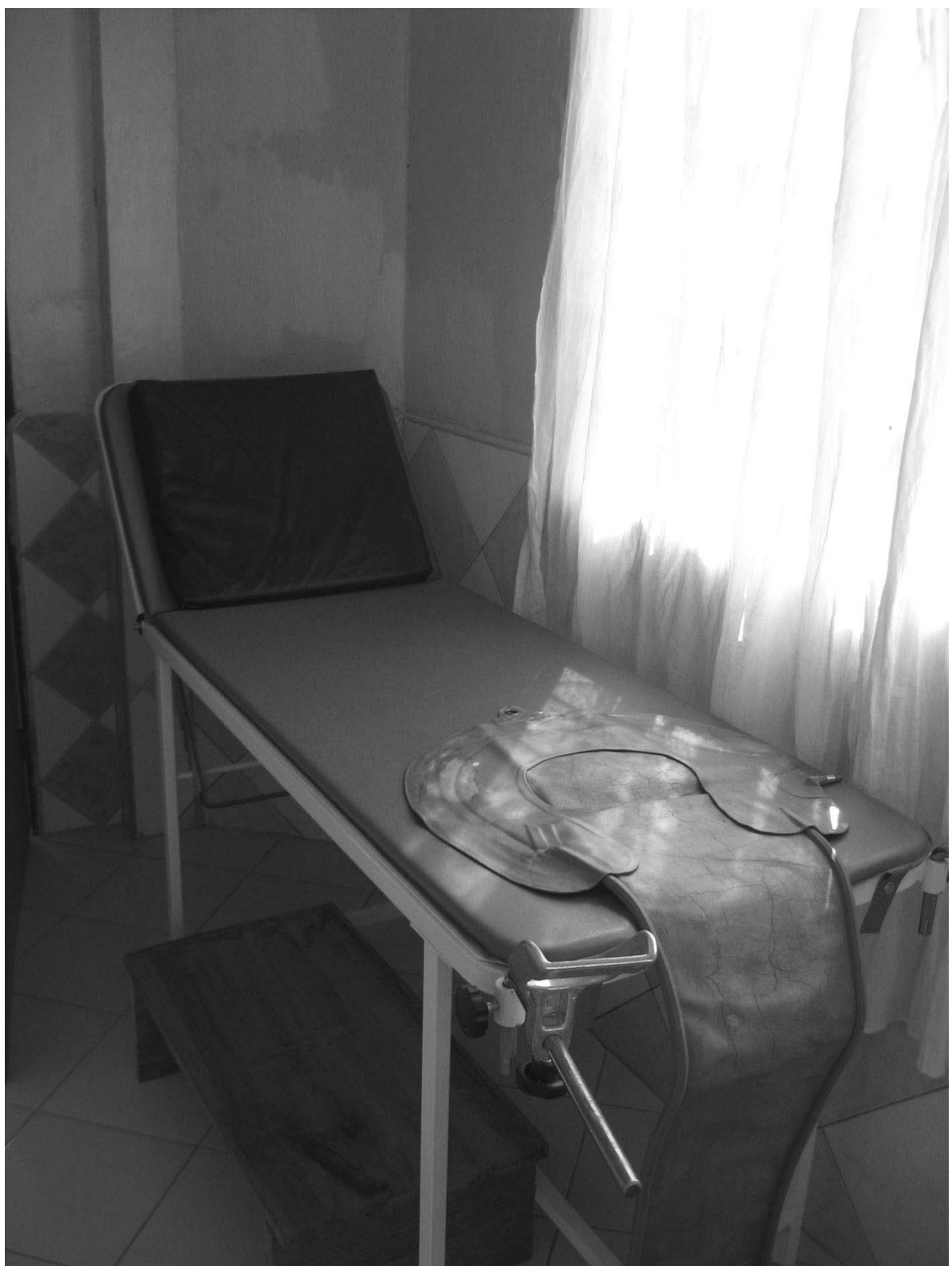

Fig. 1 Birthing table in birthing facility, Mainit, Bontoc. Photograph by the author

that would be avoided at all costs. A nongovernmental organization representative explained that no matter how much education was offered, these families would not agree to deliver outside of their homes.

When community leaders throughout the Philippines were questioned regarding how their communities would handle the situation of women who desired at-home deliveries with hilots, and did not comply with the DOHP policy, some community 


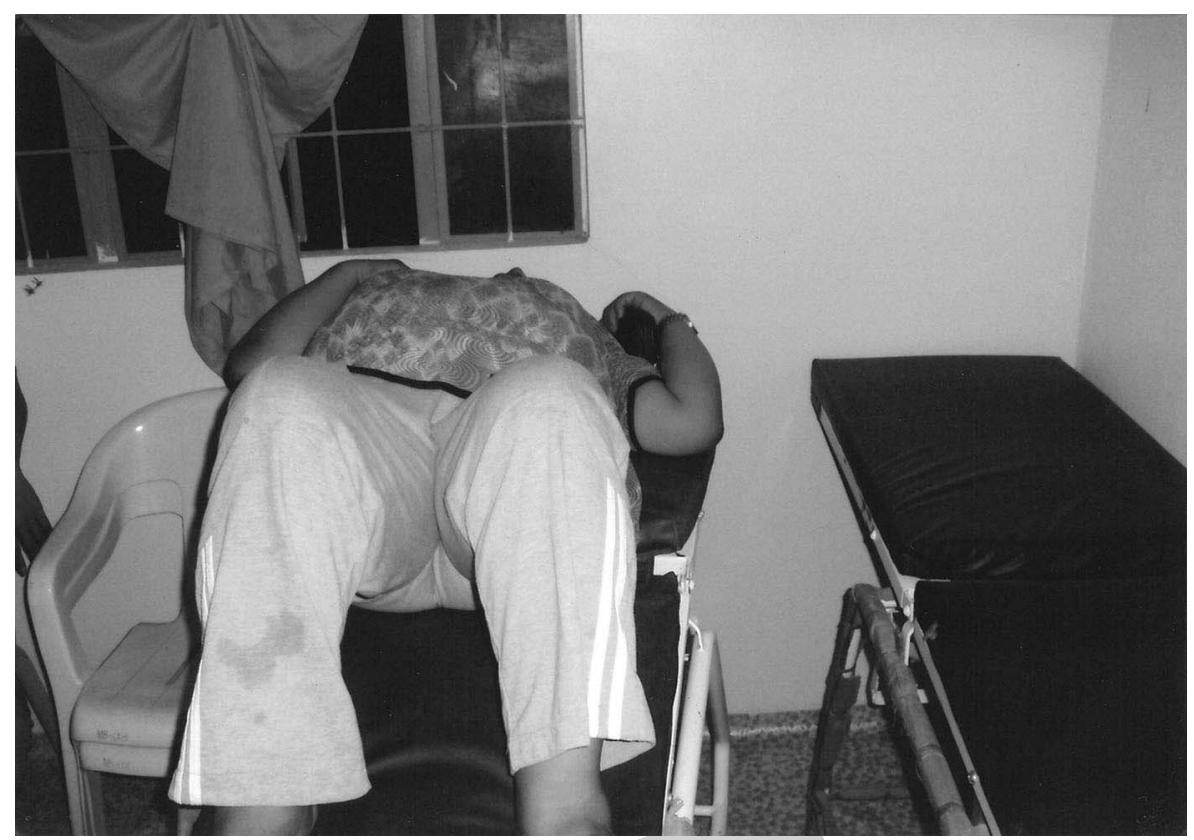

Fig. 2 Staff demonstrating how to use a birthing table, Bayombong. Photograph by the author

members and community administrators reported tactics ranging from persuasion and coercion to outright threats and apparent harassment. As of this writing, infants who are delivered by a hilot are not issued a birth certificate, as only a skilled professional is authorized to sign the certificate.

\subsubsection{Capacity and human resources}

The actual capacity for increased hospital deliveries also challenges the safety of this policy. Several chiefs of hospitals interviewed reported that their most frequent patient admission of normal spontaneous delivery was overtaxing an already overcrowded hospital system and that hospital obstetric staff have had to encourage women deemed not at risk to deliver at home. Thus, women are more apprehensive to make what is for some a very difficult and expensive journey to the hospital only to risk the possibility of being turned away. For example, in one regional hospital, normal spontaneous deliveries increased from 1,858 in 2006 to 2,116 in 2009 (12 percent increase in four years), while the number of medical staff has remained constant or decreased.

Furthermore, though this policy has significantly slashed the health care workforce by prohibiting hilots from delivering, it is of particular concern that no provisions have been offered for increasing the number of "skilled" birthing professionals. Nor does the policy address the issue of physicians who commonly refuse to work in rural areas. This professional human resource imbalance may prove particularly difficult to overcome in a country with a well-documented mass migration of medical professionals that has been supported by the state (Choy 2003).

A majority of biomedical midwife community health unit administrators interviewed (83 percent) believed the DOHP policy was neither appropriate, feasible, 
nor sustainable for their barangays. Although many midwives reported being unaware of the policy (62 percent), the remainder indicated that they ignore it. Considering that some midwife administrators can be responsible for as many as three to four different Barangay health stations, additionally having to be available around-the-clock for deliveries in several different barangays may stretch them beyond a functioning capacity. Furthermore, many midwife administrators reported good collaborative working relationships with the hilots in their barangays and reported few if any hilot delivery complications. Midwives indicated that hilots made appropriate referrals either to them or to the hospital when complications did arise. However, several hilot informants reported they had taken a patient to hospital during an emergency only to have the physicians refuse to admit the patient specifically because the patient was treated by a hilot. Yet, according to Bergström and Goodburn, even with appropriate hilot referrals, "a significant proportion of their patients do not comply with the referral advice" (2001: 85).

\subsubsection{Considering potential outcomes of safety from the eradication of hilots}

In general, appropriateness, feasibility, and sustainability for a given local context appear to have been neither assessed nor fully accounted for in this policy, as much as assumed.

A twenty-three-year-old female in Paniki, Bagabag, stated simply: "The DOH policy will not work because most women currently seek a hilot, and they will continue to do so." Hence, if the outcome of this policy is that Filipino women will continue to have at-home births with hilots, who are now no longer being trained or supplied with sterile birthing kits, then there is a justified concern for possible increases in maternal and infant morbidity and mortality and for the well-being of barangay women. This would be a particular concern for the most vulnerable women in remote, impoverished, and inaccessible areas. Thereby, the primary objective behind this policy, namely, to reduce risk and improve the safety of delivery, could be severely compromised by this very policy for safe maternal health care.

According to the ADB evaluation, "Almost all provincial and municipal health officials and service providers interviewed affirmed that training TBAs was both useful and necessary to reduce the risk of maternal mortality" (2007: 19). Similarly, Gijs Walraven and Andrew Weeks conclude: "Not training TBAs who are willing and capable to learn skills of prevention, early recognition, and management of life-threatening obstetric complications will cause more harm than good" (1999: 529).

\section{Discussion: Risk and Resistance}

The question at the heart of this research is how a system, such as biomedicine, entirely based on a hegemonic construction of safety (which biomedicine alone has the power to construct and regulate, particularly through multilateral policymaking institutions, such as the WHO), can work with groups that employ other (potentially conflicting) understandings of safety. Douglas states: "Enthusiasm for technology accounts for why the difference between them and us appeared to be a cognitive problem, a matter of knowing the real causes of things. We were supposed to be able to recognize real 
dangers, whose causes are objectively identified, backed by the authority of valid experiment and theory" (1992: 7).

Brigitte Jordan found that, although "equally legitimate parallel knowledge systems exist," which people may "move easily between ... [often] one kind of knowledge gains ascendancy and legitimacy" (1997: 56). She identifies this phenomenon as the domination of "authoritative knowledge" (56). A consequence of authoritative knowledge "is the devaluation, often dismissal, of all other kinds of knowing ... as backward, ignorant, naive" (56). The power, then, of authoritative knowledge is not that it is "correct" per se but that it is valued, reified, and universalized as normative and "truth" (58). The potential for expert or authoritative knowledge to control is also reflected in Antonio Gramsci's concept of hegemony, as the dominance and control "of a social group over the entire national society, exercised through the so-called private organizations, such as the Church, the unions, the schools" (1994: 67).

And yet Jordan and Gramsci neglect to account for the agency of the Other and their resistance to such authoritative knowledge. History repeatedly demonstrates that to ignore agency and resistance, in a foreign imposition of order, is at best naive and at worst deleterious. Reynaldo Ileto (1988: 134) identifies an event from the American colonial occupation of the Philippines in which an imposed American biomedical conception of safety undermined the very safety it was trying to ensure. To combat Asiatic cholera in 1902, infected houses were burned, residents were strictly quarantined in detention camps, medicine needed to be administered with "the use of force," and bodies of the deceased were burned. However, each of these measures threatened the integrity of the ordered systems of the Americans' intended beneficiaries. Thus, Filipinos resisted these measures, and disease was effectively exponentially spread. For example, quarantine resulted in people escaping quarantine and hiding in outlying areas, thereby rapidly spreading cholera potentially further than if quarantine had not been instituted (ibid.). Desecration of the dead via cremation was completely forbidden in Filipino ordered systems. Therefore, rather than allow them to be burned, bodies were hidden by Filipino families under homes and in swamps, which thereby served as potent vectors for cholera (ibid.).

Thus, the American attempts to control cholera, through the imposition of their paradigm of safety, provides an example of the issues that can arise when attempting to impose one's ordered systems of understanding and meaning onto the Other. Even though the US colonists perceived their paternalism as not only justifiable but, moreover, to be benevolent, their means of controlling cholera was in direct contradiction to and, in the case of cremation, in direct violation of the ordered systems of the Filipino "beneficiary," who resisted the Americans attempts to control cholera in order to protect the integrity of their own ordered systems. Hence, from the biomedical Other's imposed order, chaos ensued.

One noteworthy limitation of the Western construction of safety is its reliance upon the idea of the liberal rational "individual" of the Enlightenment, which simply does not exist in many non-Western cultures and, even after 450 years of Western colonization, does not commonly exist in the Philippines. Furthermore, what those who implemented both the colonial cholera policy in the Philippines and the policy for the eradication of hilots refuse to consider is that policies that defy local systems of order and understanding will be resisted. According to James C. Scott: "Everyday resistance is informal, often covert, and concerned largely with de facto gains ... open 
insubordination in almost any context will provoke a more rapid and ferocious response than an insubordination that... never ventures to contest the formal definitions of hierarchy and power" (1985:33). Thus, the nonuse of birthing clinics and the continued employment of hilots and home delivery are clear illustrations of resistance to a foreign imposition of safety.

\title{
9 Conclusion: Imposed Prescriptions and the Perpetuation of Intellectual Colonialism
}

\begin{abstract}
The WHO's World Health Report A Safer Future: Global Public Health Security in the Twenty-First Century (2007c) frames population health as a state and global security issue. In health securitization, population health processes are depicted as state or international security issues in which state, international, and global political economic interventions are required against named threats to public health. A similar logic can be identified in the justification for surveillance from the constructed dangers located in the current "terrorist" and securitization discourses. Both have depended on a socially shared understanding that public safety is protected and risk is reduced through the adoption of these policies and technologies, regardless of their infringement on the Other and regardless of the fact that safety and risk are being socially constructed.
\end{abstract}

Thereby, the designation of risk necessitates the intervention of the state and justifies any potential infringement upon human rights and autonomy. But what is interesting to note, in a purportedly scientific field such as risk management, is that science can conveniently ignore its own logic. For example, the scientific method by which to prove risk is now replaced by analysis in which risk is assumed or made probable. As Roberto Andorno states: "Perhaps the main originality of risk management is that measures need to be taken before definitive scientific evidence of the harmful effects becomes available" (2004: 14).

Much of the literature on risk agrees with the foundational understanding that what is defined as risk is an outcome of social construction. Boholm (2003: 159-60) states: "In social anthropology it has been taken for granted that what is to be considered a 'risk' depends entirely on cultural settings and assumptions; risks are culturally defined and selected.... The concept of risk, therefore, by definition, integrates descriptive/factual and normative components and is therefore (intrinsically) open to negotiation and contestation." Dorothy Nelkin (1989: 100) notes: "Comparisons of regulatory policies in different countries emphasize the subjective nature of risk perception." And Tim Rhodes (2002: 86) states: "The individuation of risk reduction and responsibility fails to capture the contradictory and situated pressures of risk decision making and obscures power inequalities in risk negotiation (which may relate to gender, ethnicity or other material factors)."

Similarly, safety is to be recognized as a relative political designation influenced by multiple sectors of society, particularly business. Ultimately, modern risk prevention is very often an outcome of capitalism and, in particular, neoliberalism, in which liberal individuals have the "freedom" to alter their risk through adherence to particular commodified activities or rituals. Gerda Reith notes how commodified rituals of "calculation and avoidance" comprise the growing industry of safety and risk preven- 
tion "from the fitness regimes, low-fat diets and private insurance that safeguard against ill-health and old age; to the burglar alarms, security devices and informed suspicion of dangerous areas" (2004: 395).

It is also questionable, then, if the safety and risk discourse of TM/CAM is not merely an extension of the present discourse of risk that includes the risk management of everything and that assumes that what is labeled risk can actually be managed. Both medicalization and securitization successfully construct a need for intervention and commodification. However, the commodification of, say, herbal remedies can ultimately affect access to these herbs. For example, the DOHP has manufactured four commonly used herbs that were previously picked in one's backyard for free. The justification for this was that the herb would be safer in a sanitized pill form under the biomedical control of the DOHP. However, the Philippine Institute of Traditional and Alternative Health Care, a division of the DOHP, is an independent body dependent on the profits from the manufacture of these herbs for its own economic survival. Interestingly, one local nongovernmental organization indicated that the reason the identification, preparation, and use of local herbs were made part of their teaching intervention with barangays is because many barangay members have forgotten what herbs they could freely pick and how to use and prepare these herbs. Hence, commodification, justified via biomedical understandings of safety and risk, may control what was hitherto uncontrolled and freely available. Thereby, health care can potentially be made more inaccessible through commodification that is justified for the safety of a health care practice. Furthermore, commodification may directly affect safety when, for example, herbs that may have been intended to be taken only to balance an immediate imbalance within their original paradigm are suddenly being consumed like vitamins on a daily basis within their commodified biomedical paradigm.

In conclusion, this article has illustrated that the concept of safety is a construction that is not universally understood, agreed upon, or practiced in the same manner. The normative biomedical representation and practice of safety as adopted by the WHO is not the same representation and practice of safety identified in barangays of the Philippines. Thus, safety is to be understood as socially constructed and context dependent. This article has also argued for the unpacking of assumptions that are embedded in the safety discourse. The discourse on safety assumes (a) that safety is something that can be achieved by following particular practices and (b) that, by virtue of the designation of safety, there is unsafety. The safety discourse also assumes that expertise and expert knowledge are required to combat risk and thereby that paternalism is always justifiable. As Lee Clarke (1988: 156) notes, "Expert knowledge and formal decision modelling tend to support the status quo, justifying rather than questioning political orthodoxy." Yet, through "expert knowledge," risk was actually created for Filipino women by proclaiming that they were "all at risk" and therefore rendered vulnerable and in need of intervention.

The designation of safety from "experts" assumes that a hegemonic construction of safety from the West is the universal standard to which all should adhere. This practice can be construed as following a kind of "knowledge colonialism," by which current Western knowledge and beliefs are correct and all others are understood as backward (or undeveloped) on a continuum of the West's own construction. Or, as Anthony Giddens notes, modernity is "a mode of colonising the future" (1991: 133). 
In their expert construction of safety for maternal and child health, the WHO identifies maternal and infant mortality as an outcome of unskilled birth attendants. And yet, as identified in this research, causality of infant and maternal mortality is far more complex and can be affected from the interplay of myriad social and health care factors. Similarly complex are the ways in which safety is formulated in any given context. Hence, regardless of the intended beneficence of biomedical paternalism, in order for any conception of safety to be rendered "safe" it must be reframed in terms of the complexity of the ordered systems of meaning and understanding involved in determining the safety of any given context. Otherwise, an imposition of a foreign construction of safety justified by an alien system of order can, as witnessed in this research, potentially compromise the safety of local populations and ultimately generate chaos from order.

\section{References}

ADB (Asian Development Bank) (2007). Philippines: Women's Health and Safe Motherhood Project in the Philippines. Project Performance Evaluation Reports (http://www.adb.org/Documents/PPERs/PHI/ 27010/27010-PHI-PPER.pdf, accessed 5 January 2013).

Andorno, Roberto (2004). The Precautionary Principle: A New Legal Standard for a Technological Age. Journal of International Biotechnology Law 1: 11-19.

Arnold, David, ed. (1988). Imperial Medicine and Indigenous Societies. Manchester: Manchester University Press.

Bautista, Victoria (1994). Area-Based Child Survival and Development Program: An Experiment in Devolution. U.P. Assessments on the State of the Nation, Occasional Articles Series 94-004. Quezon City: University of the Philippines, Center for Integrative and Development.S

Bergström, Staffan, and Elizabeth Goodburn (2001). The Role of Traditional Birth Attendants in the Reduction of Maternal Mortality. Studies in Health Services Organization and Policy 17: 77-96.

Bhutta, Zulfiqar A., Soofi Sajid, Cousens Simon, et al. (2011). Improvement of Perinatal and Newborn Care in Rural Pakistan through Community-Based Strategies: A Cluster-Randomised Effectiveness Trial. Lancet 377: 403-12.

Bodeker, Gerard, and Gemma Burford (2007). Traditional Complementary and Alternative Medicine: Policy and Public Health Perspectives. London: Imperial College Press.

Boholm, Asa (2003). The Cultural Nature of Risk: Can There Be an Anthropology of Uncertainty? Ethnos: Journal of Anthropology 68, no. 2: 159-78.

Bourdieu, Pierre (1977). Outline of a Theory of Practice. Translated by Richard Nice. Cambridge: Cambridge University Press.

Caplan, Pat (2000). Anthropological Perspectives on Risk. Key note lecture for Risk, Knowledge, Trust, the 10th anniversary conference of the Medical Anthropology Unit, School of Medicine, University of Oslo, September.

Carlo, WaldemarA., Shivaprasad S. Goudar, Imtiaz Jehan, et al. (2010). Newborn-Care Training and Perinatal Mortality in Developing Countries. New England Journal of Medicine 362: 614-23.

Chapman, Carleton (1974). "The Flexner Report” by Abraham Flexner. Daedalus 103, no. 1: 105-17.

Choy, Catherine C. (2006). Empire of Care. Nursing and Migration in Filipino American History. Durham, NC: Duke University Press.

Clarke, Lee (1988). Politics and Bias in Risk Assessment. Social Science Journal 25, no. 2: 155-65.

DOHP (2008). Implementing Health Reforms for Rapid Reduction of Maternal and Neonatal Mortality. Administrative Order 2008-0029. Manila: Department of Health of the Philippines.

Douglas, Mary (1966). Purity and Danger. An Analysis of Concepts of Pollution and Taboo. Abingdon, UK: Routledge.

Douglas, Mary (1992). Risk and Blame: Essays in Cultural Theory. London: Routledge.

European Commission (2008). Mid-term Review of the Health Sector Policy Support Programme (ASIE/2005/017638) in the Philippines. Brussels: Commission of the European Communities.

Flexner, Abraham (1910). Medical Education in the United States and Canada: A Report to the Carnegie Foundation for the Advancement of Teaching. New York: Carnegie Foundation. 
Giddens, Anthony (1991). Modernity and Self-Identity. Cambridge: Polity.

Gill, Christopher J., Phiri-Mazala Grace, Guerina Nicholas, et al. (2011). Effect of Training Traditional Birth Attendants on Neonatal Mortality (Lufwanyama Neonatal Survival Project): Randomised Controlled Study. British Medical Journal 342: d346.

Gramsci, Antonio (1994). Letters from Prison. 2 vols. Edited by Frank Rosengarten. Translated by Ray Rosenthal. New York: Columbia University Press.

Hogan, Margaret C., Kyle J. Foreman, Mohsen Naghavi, et al. (2010). Maternal Mortality for 181 Countries, 1980-2008: A Systematic Analysis of Progress towards Millennium Development Goal 5. Lancet 375 : $1609-23$.

Ileto, Reynaldo (1988). Cholera and the Origins of the American Sanitary Order in the Philippines. In Imperial Medicine and Indigenous Societies, edited by David Arnold, 125-48. Manchester: Manchester University Press.

Jordan, Brigitte (1997). Authoritative Knowledge and Its Construction. In Childbirth and Authoritative Knowledge, edited by Robbie Davis-Floyd and Carolyn Fishel Sargent, 55-79. Berkeley: University of California Press.

Kruske, Sue, and Lesley Barclay (2004). Effect of Shifting Policies on Traditional Birth Attendant Training. Journal of Midwifery and Women's Health 49, no. 4: 306-11.

Lee, Kelley (2009). The World Health Organization (WHO). London: Routledge.

Midhet, Farid, and Stan Becker (2010). Impact of Community-Based Interventions on Maternal and Neonatal Health Indicators: Results from a Community Randomized Trial in Rural Balochistan, Pakistan. Reproductive Health 7, no. 30: 1-10.

Nelkin, Dorothy (1989). Communicating Technological Risk: The social construction of risk perception. Annual Review of Public Health 10: 95-113.

Nilsen, P., D. S. Hudson, A. Kullberg, et al. (2004). Making Sense of Safety. Injury Prevention 10: $71-73$.

Penwell, Vicki (2009). Mercy in Action. Bringing Mother- and Baby-Friendly Birth Centers to the Philippines. In Birth Models That Work, edited by Robbie Davis-Floyd, Lesley Barclay, and Jan Tritten, 357-62. Berkeley: University of California Press.

Rajaratnam, Julie Knoll, Jake R. Marcus, Abraham D. Flaxman, et al. (2010). Neonatal, Postneonatal, Childhood, and Under-5 Mortality for 187 Countries, 1970-2010: A Systematic Analysis of Progress towards Millennium Development Goal 4. Lancet 375: 1988-2008.

Reith, Gerda (2004). Uncertain Times: The Notion of "Risk" and the Development of Modernity. Time and Society 13, no. 2/3: $383-402$.

Republic of the Philippines (1958). Republic Act 2644, an Act Regulating Midwifery Training and Practice. Manila: Republic of the Philippines.

Rhodes, Tim (2002). The "Risk Environment": A Framework for Understanding and Reducing DrugRelated Harm. International Journal of Drug Policy 13: 85-94.

Scott, James C. (1985). Weapons of the Weak: Everyday Forms of Peasant Resistance. New Haven, CT: Yale University Press.

Sibley, L. M., T. A. Sipe, C. M. Brown, et al. (2009). Traditional Birth Attendant Training for Improving Health Behaviours and Pregnancy Outcomes. Cochrane Database of Systematic Reviews 3: CD005460.

Siddiqi, Javed (1995). World Health and World Politics: The World Health Organization and the UN System. London: Hurst.

Stauffer, Robert B. (1966). The Development of an Interest Group: The Philippine Medical Association. Quezon City: University of the Philippines Press.

Starr, Paul (1982). The Social Transformation of American Medicine. New York: Basic Books.

Thacker, S. B., and H. D. Banta (1983). Benefits and Risks of Episiotomy: An Interpretative Review of the English Language Literature, 1860-1980. Obstetrical and Gynecological Survey 38, no. 6: 322-38.

USAID (2004). Newborn Health in the Philippines: A Situation Analysis. Basics Support for Institutionalizing Child Survival Project (BASICS II). Arlington, VA: US Agency for International Development.

Vuori, H. (1982). The World Health Organization and Traditional Medicine. Community Medicine 4: $129-37$.

Walraven, Gijs, and Andrew Weeks (1999). The Role of Traditional Birth Attendants with Midwifery Skills in the Reduction of Maternal Mortality. Tropical Medicine and International Health 4, no. 8: 527-29.

Webster, Andrew Joseph, Connor Merrick Douglas, and Graham Stuart Lewis (2009). Making Sense of Medicines: "Lay Pharmacology" and Narratives of Safety and Efficacy. Science as Culture 18, no. 2: $233-47$.

WHO (1975). The Traditional Birth Attendant in Maternal and Child Health and Family Planning. WHO Offset Publication no. 18. Geneva: World Health Organization. 
WHO (1977). Report of the WHO Meeting on the Promotion and Development of Traditional Medicine. Geneva: World Health Organization.

WHO (1992). Traditional Birth Attendants - a Joint WHO/UNFPA/MCH Statement. Geneva: World Health Organization.

WHO (2002a). Regional Strategy for Traditional Medicine in the Western Pacific 2002-2010. Manila: World Health Organization Regional Office for the Western Pacific.

WHO (2002b). WHO Launches the First Global Strategy on Traditional and Alternative Medicine. Press Release, 16 May. Geneva: World Health Organization.

WHO (2002c). WHO Traditional Medicine Strategy 2002-2005. Geneva: World Health Organization.

WHO (2003). WHO Guidelines on Good Agricultural and Collection Practices (GACP) for Medicinal Plants. Geneva: World Health Organization.

WHO (2005). National Policy on Traditional Medicine and Regulation of Herbal Medicines: Report of a WHO Global Survey. Geneva: World Health Organization.

WHO (2007a). WHO Guidelines for Assessing Quality of Herbal Medicines with Reference to Contaminants and Residues. Geneva: World Health Organization.

WHO (2007b). WHO Guidelines on Good Manufacturing Practices (GMP) for Herbal Medicines. Geneva: World Health Organization.

WHO (2007c). World Health Report of 2007: A Safer Future: Global Public Health Security in the 21st Century. Geneva: World Health Organization.

Paul Kadetz is an assistant professor of global health and convener of the Global Public Health program at Leiden University College, The Hague. He is also a research associate of the Refugee Studies Centre, University of Oxford, and an associate of the China Centre for Health and Humanity at University College London. He has served as an external expert researcher and as a facilitator and rapporteur for the Traditional Medicine Unit of the Western Pacific Region Office of the World Health Organization and has conducted research on integrative medicine, health care systems, and health diplomacy in China, Cuba, Guatemala, and the Philippines and in post-Katrina New Orleans. 